Revista Ítalo-Española de Derecho Procesal

Vol. 2 | 2021 pp. $15-40$

Madrid, 2021

DOI: $10.37417 /$ rivitsproc/662

Marcial Pons Ediciones Jurídicas y Sociales

(C) Renzo Cavani

ISSN: $2605-5244$

Recibido: 12/07/2021 | Aceptado: 31/10/2021

Editado bajo licencia Creative Commons Attribution 4.0 International License.

\title{
CONVENCIONES PROCESALES \\ UN ENSAYO CRÍTICO SOBRE LEGISLACIÓN PASADA, VIGENTE Y PROYECTADA DEL PROCESO CIVIL PERUANO*
}

\author{
PROCEDURAL AGREEMENTS \\ A CRITICAL ESSAY ON PAST, PRESENT AND PROJECTED LEGISLATION \\ OF PERUVIAN CIVIL PROCEDURE
}

\author{
Renzo CAVANI** \\ Profesor ordinario auxiliar \\ de la Pontificia Universidad Católica del Perú
}

\begin{abstract}
* Agradezco a mis amigos Eugenia Ariano y Giovanni Priori por la revisión de una primera versión de este trabajo, y también a Stefan Espejo, gracias a quien pude perfilar mejor las ideas sobre la interpretación del art. IX del Código Procesal Civil peruano de 1993. El presente artículo se publicó originalmente en portugués en el segundo volumen de la obra Negócios processuais (JusPodivm, 2019), coordinada por los profesores Antonio Cabral y Pedro Henrique Nogueira, a quienes agradezco por su invitación, paciencia y amistad. Luego de dicha publicación, Jordi Nieva Fenoll tuvo la gentileza de brindarme valiosos consejos y sugerencias que, en la medida de lo posible, procuré implementar. Buena parte de ellos aún siguen dando vueltas en mi cabeza. Esta versión constituye una versión revisada y mejorada de aquel capítulo de libro.

** Profesor ordinario auxiliar en la Pontificia Universidad Católica del Perú (PUCP) y docente a tiempo completo en el área «Sistema de Justicia y Solución de Conflictos» de la misma universidad. Miembro del Grupo de Investigación PRODEJUS-PUCP de la misma universidad. Doctorando en el Programa Doctorat in Dret, Economia i Empresa de la Universitat de Girona (UdG). Investigador en la Càtedra de Cultura Jurídica de la misma universidad. Magíster en derecho por la Universidade Federal do Rio Grande do Sul (UFRGS). Miembro de la International Association of Procedural Law (IAPL), Instituto Iberoamericano de Derecho Procesal (IIDP), Associação Brasileira de Direito Processual (ABDPro) e Instituto Brasileiro de Direito Processual (IBDP). CEO y cofundador de Evidence Lab. Abogado, consultor jurídico y árbitro (contacto: renzo.cavani@pucp.edu.pe).
\end{abstract}


RESUMEN: El presente ensayo contiene un diagnóstico y una propuesta sobre las convenciones procesales en el proceso civil peruano. Comienza con una aproximación histórica a los orígenes del Código Procesal Civil peruano de 1993, mostrando que esta legislación tiene sus raíces en un modelo en el que el juez tiene grandes poderes y los de las partes fueron claramente recortados. Continúa con un esfuerzo interpretativo para permitir las convenciones procesales (basado en el derecho fundamental a la libertad contractual) y concluye con una breve exposición en el Proyecto de Nuevo Código Procesal Civil sobre este tema.

PALABRAS CLAVE: Convenciones procesales, Código Procesal Civil peruano de 1993, poderes del juez, libertades de las partes.

ABSTRACT: This essay contains a diagnostic and a proposal about procedural agreements in Peruvian civil procedure. It starts with a historical approach to the origins of Peruvian Civil Procedure Code of 1993, showing that this legislation has its roots in a model in which the judge has great powers and those of the parties were clearly diminished. It follows with a hermeneutical effort to allow procedural agreements (based on the right of contractual liberty) and concludes with a brief exposition about the project of new Code on this topic.

KEYWORDS: Procedural Agreements, Peruvian Civil Procedure Code, Judicial Powers, Parties' Liberties.

SUMARIO: 1. INTRODUCCIÓN.-2. DIAGNÓSTICO: LAS CONVENCIONES PROCESALES EN EL PROCESO CIVIL PERUANO. 2.1. El CPC-93 entre ideología y dogmática. 2.2. El art. IX del Título Preliminar del CPC-93: ¿Imposibilidad de negociación procesal atípica? 2.3. Los negocios procesales típicos en el CPC-93 (con especial énfasis en las convenciones procesales).-3. PROPUESTA: ¿QUÉ CAMINO ADOPTAR? A PROPÓSITO DEL PROYECTO DE NUEVO CÓDIGO PROCESAL CIVIL (PRCPC).-4. CONCLUSIONES.-5. REFERENCIAS BIBLIOGRÁFICAS.

\section{INTRODUCCIÓN}

Muchas son las razones por las cuales el tema de los negocios jurídicos procesales merece ser estudiado por los procesalistas hispanoamericanos. Sería posible mencionar por lo menos tres de ellas:

i) La complejidad del abordaje teórico-dogmático, que a su vez puede tener dos dimensiones: (a) en una dimensión teórica se exige que se recurra a la teoría del derecho, específicamente, la difícil teoría del hecho jurídico (que, por lo menos en el Perú, se estudia a partir de los trabajos de civilistas sin mucha preocupación con un abordaje aplicable a otras ramas jurídicas); y (b) en una dimensión dogmática se exige un trabajo analítico respecto de las posibilidades interpretativas que ofrece cada particular derecho positivo.

ii) El impacto directo en el clásico debate "garantismo»vs. "publicismo», y, más concretamente, en los espacios del ejercicio de la autonomía de la voluntad de las partes en el proceso.

iii) Las ventajas que pueden traer los negocios jurídicos procesales tanto para el juez como para las partes, con específica preocupación sobre los límites en cuanto a la validez y a la eficacia. 
Mi objetivo con este texto no es desarrollar con profundidad esos asuntos que vienen siendo trabajados a través de importantes esfuerzos doctrinarios ${ }^{1}$, sino enfocar la atención en la regulación de las convenciones procesales en el Código Procesal Civil peruano (CPC-93), con la intención de ofrecer una apreciación crítica, sea para estudiosos o extranjeros, de esta parte del derecho peruano. Pero no solo ello: también se trata de contribuir para sentar las bases para una futura reforma legislativa.

De allí la razón por la que el trabajo viene dividido en dos grandes partes: un diagnóstico y una propuesta. Para construir el diagnóstico, creo que es indispensable partir de una premisa que será analizada de forma breve, si bien que ella podría constituir un largo ensayo. Dicha premisa, a su vez, se divide en dos dimensiones. El CPC-93, por lo menos desde el cambio legislativo ${ }^{2}$, significó (i) un tránsito entre el «procedimentalismo» y el así llamado «procesalismo» y (ii) un paso de una ideología que apostaba más por una mayor presencia de las partes en el proceso hacia una marcadamente publicista, en que hubo un claro declive de los poderes privados y un incremento sustancial de los del juez. La primera dimensión tiene que ver con la modelación de diversos institutos del derecho procesal civil inspirados - directa o indirectamente- en las lecciones de la doctrina italiana "científica» de la primera mitad del siglo Xx. La segunda dimensión, a su vez, se refiere a la división de tareas entre juez y partes: se apostó fuertemente por un modelo en que el juez pasa a tener amplios poderes de dirección del proceso e instructorios, atribuyéndole el deber principal de prestar tutela a los derechos de las partes, promoviendo la paz social y la justicia, reduciendo drásticamente, para ello, los poderes de las partes sobre el procedimiento, concretamente los espacios de ejercicio de libertad sobre la configuración del procedimiento.

Este panorama, según pienso, es importante para justificar y entender las reglas que dificultan la posibilidad de interpretar a favor de la existencia de una cláusula atípica negocial en el CPC-93, y también para comprender los escasos dejados por el legislador peruano para las convenciones procesales ${ }^{3}$.

1 Remito a la doctrina que se ha pronunciado sobre el asunto: Almeida (2015); Ataíde Jr. (2015); Cabral (2018); Carneiro da Cunha (2015); Di Spirito (2017); Didier Jr. (2015 y 2015a); Didier Jr. \& Nogueira (2011 y 2015); Godinho (2015); Nogueira (2016). Tuve la oportunidad de coordinar, juntamente con el Prof. Pedro Henrique Nogueira, una obra inédita en el Perú (y, hasta donde llega mi conocimiento, en la literatura en lengua española en general) sobre las convenciones procesales: Nogueira \& Cavani (2015).

2 Hago mención al cambio legislativo porque las alteraciones en la cultura jurídica peruana (sea en la práctica judicial, sea en la práctica forense) luego del CPC-93, requerirían otro tipo de análisis y demostraciones.

3 Para los objetivos de este trabajo, puede servirnos la definición de Cabral (2018: 74): «Convención (o acuerdo) procesal es el negocio jurídico plurilateral mediante el cual las partes, antes o durante el proceso y sin la necesidad de intermediación de ningún otro sujeto, determinan la creación modificación y extinción de situaciones jurídicas procesales, o alteran el procedimiento». Dependiendo de la teoría del hecho jurídico escogida y, también, del concepto de negocio jurídico, es posible que la definición abarque otras figuras, como, por ejemplo, las resoluciones judiciales (cfr. Nogueira, 2016: 199 ss.). Asimismo, nótese que una convención también puede celebrarse mediante una oferta y aceptación distantes en el tiempo, cada una de ellas realizada en actos procesales individualizados (y, como 
Es interesante, sin embargo, visualizar que, aun siendo una legislación procesal típicamente publicista, no llegó a sofocar completamente el ejercicio de la libertad de las partes.

No obstante, la construcción de este diagnóstico también es muy útil para reflexionar cuál sería el futuro de la negociación procesal desde un análisis del Proyecto de Reforma del CPC-93 (PRCPC) elaborado por una Comisión nombrada por el Ministerio de Justicia y Derechos Humanos del Perú, y publicado en $2017^{4}$, pero que todavía continúa siendo trabajado.

Al final del trabajo, se demostrará que el proceso civil peruano se estaría encaminando hacia una lenta pero progresiva apertura a las convenciones procesales y, más ampliamente, a un espacio más dialogal entre las partes que pueda llegar a amainar la preponderancia del rol del juez en el proceso.

\section{DIAGNÓSTICO: LAS CONVENCIONES PROCESALES EN EL PROCESO CIVIL PERUANO}

\subsection{El CPC-93 entre ideología y dogmática}

Si se quisiese emprender un estudio comparado vertical (histórico) respecto del CPC-93 sería posible identificar, como en muchos otros ordenamientos jurídicos, dos elementos que convergieron en la reforma del proceso civil peruano: una dogmática y otra histórico-ideológica ${ }^{5}$. En ambas dimensiones, por cierto, fueron decisivas las influencias del Código Procesal Civil y Comercial de la Nación argentino, de 1968, y el Código Procesal Civil modelo para Iberoamérica, de $1988^{6}$. La vertiente dogmática no será el foco de atención aquí, pero es posible decir que el CPC-93 en cierta medida buscó acoger teorías y doctrinas de la así llamada «etapa cientificista del proceso», correspondiente a la primera mitad del siglo Xx, principalmente de Italia. Para entender esto hay que volver la mirada hacia el pasado.

El Código de Procedimientos Civiles peruano de 1912 (CPC-12), como muchas otras legislaciones en otras latitudes y otros tiempos, todavía no había recibido la fuerte influencia de la pandectística germánica a través de Chiovenda y su Escuela, así como el incesante trabajo conceptual, sea teórico (por

\footnotetext{
es obvio, puede ser expresa o tácita). El mejor ejemplo es el pacto sobre la competencia: se demanda ante un juez territorialmente incompetente, lo cual significa una oferta del demandante de llevar a cabo el proceso ante un juez diferente al que la ley manda como regla general (digamos: el del domicilio del demandado) o al que las partes acordaron previamente. En esta hipótesis, la prórroga de la competencia del demandado se efectivizaría cuando acepta expresamente la competencia del juez inicialmente incompetente o cuando no plantea la excepción de incompetencia.

${ }^{4}$ Ver epígrafe 3.

${ }^{5}$ Cfr. Abreu (2014). Sin embargo, no estoy de acuerdo con el autor en la afirmación de que se habría dado un tránsito del Estado liberal al Estado social. En realidad, fue tan diferente la evolución del proceso civil en la propia Europa que dicho cambio histórico solo podría ser defendida en ciertas latitudes y a partir de experiencias históricas específicas.

${ }^{6}$ Hice la comparación respecto del tema de las nulidades en otro texto: Cavani (2014: 81 ss.).
} 
ejemplo: teoría de la acción, medidas cautelares y cosa juzgada), sea dogmático (presupuestos procesales, litisconsorcio, etc.) ${ }^{7}$, que esta desarrolló.

El CPC-12 no tuvo como objetivo la transformación de la cultura jurídica procesal peruana ni mucho menos constituir un monumento legislativo que refleje los avances de la doctrina en aquella época; por el contrario, el esfuerzo se orientó a la reedificación de la legislación para construir un proceso más célere, simple e inteligible y, por tanto, más efectivo que el consagrado en el Código de Enjuiciamientos en Materia Civil de 1852, que era visto como una legislación con reglas y procedimientos extremadamente complejos ${ }^{8}$. En una palabra: fue una tarea de sistematización ${ }^{9}$.

Prueba de ello es la Exposición de Motivos del CPC-12, preparada por la Comisión de Reforma Procesal que, en realidad, era una extensa obra de comentarios al entonces proyecto de Código. En lo particular, desde la primera página se aprecia la intención de los reformadores:

«La ley del procedimiento, como lo indica su nombre, tiene por objeto único establecer las reglas de la sustanciación ó la manera de proceder, tanto respecto de los que ocurren al juez, como de este y de los funcionarios ó auxiliares que intervienen en el proceso, y de las formas ó actuaciones propiamente dichas. No es objeto de esa ley la organización ó manera de ser de ese poder, asunto que concierne á la Constitución del Estado y à la Ley Orgánica del Poder Judicial» ${ }^{10}$.

El CPC-12 era un código legalista y formalista, en el sentido que tenía una preocupación especial por regular con detalle las formas de la ley, que apostó decisivamente por la escritura, y en nada quiso innovar en cuanto a la orientación ideológica. Como auténtico heredero del viejo Código de 1852 y, por tanto, con claros vestigios medievales, el CPC-12 podría ser calificado como «privatista» - o, mejor, «liberal»— a partir de datos legislativos específicos, como la flexibilidad para la presentación de pruebas (era opcional acompa-

7 Cfr. Raatz \& Anchieta (2018).

8 El Código de Enjuiciamientos en Materia Civil de 1852 fue la primera legislación en materia procesal civil de la República del Perú. Hasta ese año, hubo leyes propiamente peruanas sobre la organización del Poder Judicial (por ejemplo, el Reglamento de Tribunales) y decretos orientados a la regulación de la nueva Corte Suprema peruana y el recurso de nulidad. Sin embargo, aun cuando en 1821 ocurriera la Independencia del Perú —-materializada bélicamente en 1824 - y se haya promulgada la primera Constitución peruana en 1823, muchas leyes españolas que regulaban el derecho civil y el derecho procesal rigieron hasta 1852. En lo que corresponde al proceso, el Libro XI de la Novísima Recopilación de 1805 acogió en gran medida la regulación del proceso de la Nueva Recopilación de 1567 (así como otras leyes y compilaciones), y ambos diplomas tienen como base fundamental el Libro III de las Siete Partidas, texto romanizado e introducido en 1348 como fuente supletoria que, posteriormente, ganara una decisiva relevancia entre los juristas y la práctica forense (cfr. ampliamente, Montero Aroca, 2000). El Código de Enjuiciamientos de 1852 era, por tanto, una derivación de las Partidas y, así, teniendo como fuente una legislación medieval, poseía una construcción procedimental compleja, prolífica en definiciones y formalismos, revelándose, además, muy poco sistemática. Empero —nótese bien - también tuvo como fuente importante de inspiración la práctica forense peruana (Ariano, 1998: 125). A pesar de ello, a juicio de Julián Guillermo Romero, fue un código importante porque sirvió para acabar con la «anarquía de las leyes [españolas] derogadas» (Romero, 1914: xii).

9 Romero (1914: xxv).

10 Comisión de Reforma Procesal (1912: 1). 
ñarlas en la petición inicial ex art. 308 ${ }^{11}$; y en el caso del instrumento público y de la confesión, podían ser ofrecidas en cualquier estado del proceso ex arts. 364 y 409) y la posibilidad de presentar excepciones en segundo grado con la posibilidad de producir pruebas sobre ellas (art. 1103).

Empero, hay aspectos muy importantes que, cuando menos, hacen que el CPC-12 no sea tan privatista como se podría pensar. Si bien el juez no impulsaba de oficio el proceso, todo escrito se presentaba ante él, por lo que debía autorizar los actos de parte. Esto significa que sí tenía un control importante sobre ellos. Asimismo, el juez tenía el poder de expedir apremios de detención de las partes (art. 184 ss.), de ordenar pruebas de oficio «que juzgue necesarias» salvo la prueba testimonial y el juramento decisorio (art. 349) $\mathrm{y}$, en general, de intervenir en la práctica de la prueba, como preguntar a testigos (art. 477) y dar instrucciones a los peritos (arts. 495 ss.). A partir de esto podría concluirse, a partir de un análisis rigurosamente legislativo, que el CPC-12 apostó más por un procedimiento flexible a favor de las partes, pero no exactamente por un proceso abiertamente controlado por ellas.

El rol del juez del CPC-12 y los poderes conferidos a él, como suena natural, están en las antípodas de un modelo claramente privatista o controlado por las partes, como es el caso del Codice di Procedura Civile italiano de 1865, el cual preveía que las notificaciones eran realizadas por las propias partes (art. 39), incluyendo la citación mediante oficial de justicia (art. 135), luego de lo cual se comparecía ante el pretor, siendo posible que haya sucesivas e ilimitadas réplicas y dúplicas entre las partes (art. 165) ${ }^{12}$.

Tampoco es posible confundir el CPC-12 con otros aspectos que tienen que ver más con la cultura jurídica que con el propio cuerpo normativo. Algunos de ellos, por ejemplo, son la forma cómo la práctica forense y judicial recibieron la legislación y cómo trabajaron con ella a lo largo de los años; el hecho de que las principales producciones literarias en la vigencia del CPC12 sean comentarios exegéticos a la ley procesal, salvo pocas excepciones ${ }^{13}$;

11 La numeración de los artículos pertenece a la versión original.

12 Para un análisis sobre el Codice de 1865 y, en lo particular, sobre el poder de las partes y el rol del juez, cfr. Taruffo (1980: 115 ss.).

13 Cfr. Alzamora (1953, que fuera su tesis de doctorado en derecho sobre la teoría de la acción procesal; 1953a, con ediciones posteriores en 1959, 1965, 1967, 1975 y 1981; y 1966, con una edición posterior en 1968). Es curioso notar que Mario Alzamora Valdez no puede ser catalogado rigurosamente como un procesalista. Graduado en filosofía y derecho, tenía una fuerte formación filosófica al punto de escribir sobre temas profundos de esta materia (por ejemplo: fenomenología, metafísica, filosofía tomista, etc.). En el campo del derecho, escribió libros sobre introducción al derecho, filosofía del derecho, derecho constitucional, derecho municipal, derechos humanos, además de las obras sobre derecho procesal citadas, donde mostraba conocimiento de notorios representantes de la doctrina procesal italiana, francesa, alemana, portuguesa y argentina de la primera mitad del siglo xx, y también de diversas legislaciones extranjeras. Alzamora fue el primer jurista peruano en tratar sistemáticamente los conceptos de proceso, acción y jurisdicción, y otros institutos de la teoría del proceso, lejos de comentarios exegéticos sobre la legislación procesal vigente y, además, fue un gran defensor de la necesidad de la reforma estructural del código en la línea de las propuestas chiovendianas (véase al respecto los elogiosos y conmovedores homenajes de diversos juristas peruanos que, hoy, ya son consagrados: VVAA, 1988: 685 ss.). Todo este programa fue plasmado en su clásico libro Derecho procesal civil: Teoría 
o si es que la enseñanza del derecho procesal en las universidades consistió fundamentalmente en la repetición y/o memorización de las reglas legales y números de los artículos ${ }^{14}$.

En efecto, si acaso la práctica forense y judicial peruana a lo largo del siglo xx se caracterizó por la chicana y la dilación de los procesos, por el uso indebido de la flexibilidad para los actos de postulación o para las pruebas, por el abuso de los pedidos de nulidad en sede recursal o por la deficiente organización del Poder Judicial en los juzgados civiles (con los secretarios dueños de un gran poder en la tramitación de la causa, lo que terminaba por distanciar a las partes del juez ${ }^{15}$, es dudoso responsabilizar por todo ello, aunque sea parcialmente, al CPC-12 ${ }^{16}$.

Tampoco es posible entender, como lo hace una parte de la doctrina peruana, que el CPC-12, por el hecho de ser una legislación «procedimentalista», sería una "copia actualizada» de la Ley de Enjuiciamiento Civil española de $1881^{17} \mathrm{y}$, simultáneamente, que cargaría una vena privatista del modelo francés (esto es, del Code de Procédure Civile de 1806), afirmando inclusive que este habría sido, con variantes, un antecedente directo del proceso español hasta 2000 y de los códigos sudamericanos del siglo xx 18, incluyendo el peruano.

La LEC de 1881 se inspiró, como es claro, en la legislación española previa, incorporando elementos del derecho común de las Siete Partidas que subsis-

general del proceso, típico libro de introducción al derecho procesal, cuya primera edición es de 1953 (es sintomático que casi no existan citas de autores peruanos). La continuación de esta obra es el libro Derecho procesal civil: teoría del proceso ordinario, cuya primera edición es de 1966. Allí pasa a realizar una exposición sistemática de los principales institutos procesales regulados por el CPC-12, pero, fiel a su estilo, rechaza el método exegético y trabaja intensamente con referencias históricas del derecho español y del Código de 1852, así como de la doctrina y derecho extranjero — tanto el vigente y también el antiguo, buscando comprender mejor las particularidades de nuestra legislación. El papel de Alzamora Valdez fue expresamente reconocido, en 1987, por Monroy Gálvez (2017: 124-126). Por cosas de la vida, Alzamora falleció en 1993, en el mismo año en que entró en vigor el CPC.

14 Monroy Gálvez (2010: 13) afirma que el proceso civil peruano bajo la vigencia del CPC-12 era formalista, anacrónico y elitista. Aunque no existen datos empíricos precisos, con esta afirmación sería posible concordar solo si es que se refiere a la cultura jurídica peruana, de la cual el CPC-12 no es más que un engranaje.

15 Aunque esto obedece más a un conocimiento experiencial y no empírico. Como es claro, solo el segundo sirve para dar sustento a afirmaciones, sobre todo cuando se escribe en textos académicos.

${ }_{16}$ Curiosamente, en un texto reciente, Monroy Gálvez, afirmó que «nada de lo malo que ha ocurrido en nuestro sistema judicial en los veinticinco años de vigencia del CPC le es atribuible a este. Si esa afirmación fuera cierta, así lo creo, es evidente que la sustitución [del Código] no es una necesidad actual» (2018: 4). Cabría preguntarse, entonces, por qué el mismo autor, con tamaña dureza, justificó la necesidad de la reforma de inicios de la década de los noventa culpando al viejo código. Sin embargo, existiendo hoy una innegable crisis en la justicia civil peruana, según el autor, el código vigente quedaría «libre de toda culpa» (p. 4).

17 Monroy Gálvez (2009a: 8).

18 Monroy Gálvez (2009: 17). Dicha afirmación ya estaba presente en un texto del autor que data de 1988, diciendo que el CPC-12 se encuentra «sólidamente sustentado en los fundamentos de la llamada Filosofía Individualista, es decir, es expresión de la concepción liberal emanada de los postulados de la Revolución Francesa» (Monroy Gálvez, 2010: 88). 
tieron en -y pasaron a través de - la Ley de Enjuiciamiento Civil de $1855^{19}$. Sin embargo, una simple lectura del CPC-12 que vaya más allá de la estructura de las secciones y capítulos iniciales, revela que no es, ni por asomo, una «copia actualizada» de aquella. Las hoy derogadas legislaciones española y peruana compartieron un fuerte núcleo medieval, un apego a dejar menos campo al arbitrio judicial ${ }^{20}$, pero tuvieron grandes matices producto de muchas otras circunstancias culturales locales que no pueden ser olvidadas.

Además de ello, la Partida III colocó a las partes como «señores de los pleytos ${ }^{21}$, esto es, como titulares del derecho discutido y del cauce por el cual este debía discurrir. De allí que sea muy natural que las partes dispongan de una gran amplitud de medios de ataque y defensa a fin de que el pleito sea concluido definitivamente ${ }^{22}$. Pero todo ello proviene de la herencia del derecho común hispánico, que dio origen, en el siglo XIII, a las Siete Partidas. No sería posible, como es claro, hasta por una consideración cronológica, equiparar ese contexto medieval-hispánico con el liberalismo de la revolución francesa y de los códigos napoleónicos —que pretendieron romper con el pasado medieval ${ }^{23}$ - específicamente con el Code de Procédure Civile de 1806 y sus derivaciones directas, como la inmensa mayoría de los códigos procesales en la Italia de la restauración luego de la ocupación napoleónica y el Codice di Procedura Civile italiano de $1865^{24}$, o inclusive las legislaciones visiblemente

19 Montero Aroca (2000: 594 ss.). Esclareciendo que la LEC de 1881 proviene directamente de la LEC de 1855, pero con la adicción de nada menos que 767 artículos, cfr. Manresa y Navarro (1881: 10).

20 Manresa y Navarro (1881: 10).

21 Montero Aroca (2000: 586).

22 Montero Aroca (2000: 586-587).

23 Más allá que, en el específico caso del Code de Procédure Civile de 1806, a pesar de haber derogado todas las leyes, costumbres, usos y reglamentos sobre el proceso civil (ver art. 1041), efectivamente lo haya conseguido. En realidad, el Code significó, en buena medida, una continuidad de la vieja Ordonnance Civile de 1667, aunque, eso sí, con innovaciones importantes (como en el caso de la nulidad procesal) orientadas a simplificar el rito. La auténtica preocupación de los revolucionarios giró en torno a la completa implementación del Code Civile, el combate de algunas prácticas, como la chicana y los excesivos costos y, sobre todo, en el desmantelamiento del sistema de justicia del Ancien Regime (Wijffels, 2005: 26, 31).

24 Destacando la profunda vena francesa en Italia, cfr. Taruffo (1980: 55 ss.). Hay, sin embargo, un tema importante. El art. 254 del Code preveía la posibilidad de ordenar prueba de oficio: «Le tribunal pourra aussi ordonner d'office la preuve des faits qui lui paraîtront concluans, si la loi ne le défend pas». Esto, sin embargo, no puede entenderse como un poder instructorio fuerte del juez. En efecto, este artículo se encontraba en el título XII «Des Enquêtes», esto es, la prueba testimonial, por lo que solo se restringe a esta. En este ámbito, según Loret, «este poder está fundado en la máxima que los jueces pueden ordenar todas las pruebas y exigir toda información aptas para esclarecer su opinión» (1812: 118). Asimismo, debía leerse de conformidad con la regulación del Code Civile (arts. 1341 y ss.), en donde no podría ordenarse una prueba testimonial respecto de convenciones realizadas entre las partes y plasmadas en documento (frente a un notario o no) respecto de cualquier acto que involucre la suma de 150 francos o más. Esto, para la ley, era un hecho concluyente, sobre el cual no cabía prueba testimonial. Pero no solo ello. Tal como ejemplifica Boitard, si se reclamaba una suma de 10.000 francos y el demandado negaba el hecho, la prueba del hecho era concluyente: la ley prohibía la prueba testimonial, pero el demandado podía no invocar dicha prohibición y consentir que se realice dicha prueba. Frente a la posibilidad que los jueces se nieguen a ello, Boitard señala que debía prevalecer la libertad de las partes (Boitard, 1854: 468-469). 
influenciadas tales como la Zivilprozessordnung alemana de $1877^{25}$. Más bien, si es que hubo una legislación que, por fuerza de la tradición del viejo juicio ordinario, no recibiera la profunda influencia del modelo francés, fue precisamente la LEC de 1855, cuya base fue la misma que la LEC de $1881^{26}$. Aquí habría pesado más la vieja tradición.

Así, afirmar que el CPC-12 en el Perú es «copia» de la LEC de 1881 y que también (o por tal razón) tendría inspiración en el modelo francés solo por el hecho de que ambas legislaciones, en mayor o menor medida, hayan consagrado un modelo con mayor prevalencia de las partes frente al juez (más, por cierto, el CPC-12 que su par español, pero lejos del Code de Procédure Civile o sus derivaciones italianas), me parece un anacronismo y una exagerada simplificación. Peor aún: podría llegar a ser una manipulación ideológica para justificar los avatares del CPC-93.

El CPC-12, a lo largo de su vigencia, sufrió diversos cambios ${ }^{27}$ y otras leyes ya revelaban una progresiva asunción de una tendencia hacia el incremento de los poderes del juez ${ }^{28}$. No obstante, la reforma procesal de 1993 abrazó profundamente el así llamado «publicismo», reflejado en la preponderancia de los poderes del juez sobre los de las partes ${ }^{29}$ que sufrieron una muy severa reducción, al punto de llegar, inclusive, a afectar el derecho al contradictorio $^{30}$. El juez pasa a ser el gran actor del proceso, con un fuerte

${ }_{25}$ Cfr. Beneduzi (2015: 21), quien afirma que la ZPO no es un mero subproducto del Code de 1806.

26 Montero Aroca (2000: 598-599).

27 Las principales fueron la del Decreto Ley N. ${ }^{\circ} 20236$, de 1973, el Decreto Legislativo N. ${ }^{\circ} 127$, de 1981 (ninguno de ellos alteró la sustancia) y el Decreto Ley N. ${ }^{\circ} 21773$, de 1977, que introduce el impulso de oficio.

28 Un caso paradójico es el proceso agrario peruano. Luego de la reforma agraria de 1969 ordenada por el gobierno militar (Decreto Ley N. 17716, que sustituyó la tímida ley de reforma agraria de 1963), que llevó a la confiscación de las tierras de los hacendados en el país entero en favor de sus trabajadores, se creó un fuero agrario que funcionó como una auténtica jurisdicción independiente, con una ideología muy diferente al proceso civil común. Por ejemplo, más allá de un proceso muy sumario en cuanto a los plazos y oral en su estructura, se debían aplicar oficiosamente las normas favorables a los campesinos (art. $154 \S 2$ del Texto Único Concordado del Decreto Ley N. 17716) y el juzgado debería ordenar cualquier prueba que considere pertinente, inclusive inspecciones judiciales de oficio sin citación de las partes (art. 165 §§ 2 y 6). Cfr. Dongo Denegri (1986: 596 ss.).

29 Pero el CPC-93 también estableció diversas reglas que impiden recurrir contra diversas resoluciones interlocutorias (algunas de ellas muy graves para el proceso, como ordenar una prueba de oficio - art. 194) y muchos poderes discrecionales, como, por ejemplo, salvo previsión expresa de ley, poder determinar si la apelación de autos tendrá o no reserva de trámite (art. 369 CPC - sobre el punto, cfr. Cavani, 2018: 114 ss.).

30 Es el caso, por ejemplo, del art. $637 \S 1$, que ordena que la medida cautelar debe ser concedida o denegada sin escuchar a la otra parte, en cualquier hipótesis, salvo el caso de la medida de administración provisional de la empresa (art. 670) y otras disposiciones especiales que solo fueron plasmadas muchos años después (por ejemplo: art. 15 § 3 del Código Procesal Constitucional, en lo que toca a la tutela provisional orientada a suspender efectos de actos administrativos emitidos en el contexto de legislación municipal o regional, y el art. 159 inc. 5 del Código Tributario, en el caso de tutela provisional para suspender los efectos de la ejecución administrativa). En el caso del proceso de ejecución, el art. 700 (hoy art. 690-D), frente a la orden ejecutiva de cumplimiento de la obligación, prevé la reducción de las defensas del ejecutado mediante la contradicción, sin reconocer la posibilidad de un proceso plenario posterior. 
papel de dirección (art. II) ${ }^{31}$, responsable por resolver el conflicto de intereses con relevancia jurídica, efectivizando los derechos sustanciales y traer "paz social con justicia» (art. III) ${ }^{32}$ y de promover la igualdad efectiva entre las partes (art. VI) ${ }^{33}$. Por tanto, el proceso incorpora la protección del interés del Estado en la solución de conflictos, sobreponiéndose al interés de las partes, ya que el proceso privado sería «signo de obsolescencia grave o aguda, según se mantengan vigentes ordenamientos estrictamente ceñidos a las tesis decimonónicas del liberalismo individualista, o a los postulados romano-canónico-comunes del ordo iudiciorum privatorum» ${ }^{34}$. Esto tal vez no llegue a sorprender del todo porque el CPC-93, rigurosamente, fue elaborado en una etapa preconstitucional: es anterior a la Constitución de 1993 y, en general, a la constitucionalización del ordenamiento jurídico que recién, en el Perú, operó por labor del Tribunal Constitucional a partir del año 2000, luego de la caída del régimen dictatorial de Alberto Fujimori.

El CPC-93 vio la opción por el «publicismo» - y, también, por el «cientificismo» en la posivitización de los institutos procesales- como una «necesidad histórica» e, inclusive, según uno de los juristas que participaron más activamente en su elaboración y que más ha defendido la entonces nueva legislación, esta significó un "salto de etapas» y, además, que podía contribuir para promover el «pasaje de un Estado liberal hacia un Estado social» y transformar la realidad del juez burócrata y formalista por un garante de la justicia que interprete el enunciado desde la perspectiva de los valores ${ }^{35}$.

Lo cierto es que cuando mínimo es muy dudoso hablar de un "salto de etapas» si es que, en líneas generales, el tránsito a nivel dogmático e ideológico también se habría experimentado en otras experiencias jurídicas. El Perú, en realidad, habría llegado a sentir muy tarde los vientos del publicismo. Desde este punto de vista, al menos, el CPC-93 se muestra como un código viejo. Asimismo, no queda muy claro cómo es que una legislación procesal civil podría contribuir para un cambio de una magnitud tan grande que, más bien, tiene que ver con transformaciones políticas, sociales y económicas muy sensibles. Finalmente, es válido preguntarse si acaso el CPC-93 no habría contribuido

31 « 1. La dirección del proceso está a cargo del Juez, quien la ejerce de acuerdo con lo dispuesto en este Código. § 2. El Juez debe impulsar el proceso por sí mismo, siendo responsable de cualquier demora ocasionada por su negligencia. Están exceptuados del impulso de oficio los casos expresamente señalados en este Código».

32 « 1. El Juez deberá atender a que la finalidad concreta del proceso es resolver un conflicto de intereses o eliminar una incertidumbre, ambas con relevancia jurídica, haciendo efectivos los derechos sustanciales, y que su finalidad abstracta es lograr la paz social en justicia. [...]». Es verdad que el art. III habla de "fines del proceso», pero aquí el proceso es claramente medio para que el Estado, por medio del juez, imponga su autoridad. Se trataría, más rigurosamente, de «fines de la jurisdicción» como interés público, sobrepuesto a los intereses privados, de solucionar el conflicto.

33 «Párrafo único. El Juez debe evitar que la desigualdad entre las personas por razones de sexo, raza, religión, idioma o condición social, política o económica, afecte el desarrollo o resultado del proceso".

34 Monroy Gálvez (1996: 71).

35 Monroy Gálvez (2018: 5). 
por reforzar el burocratismo. En todo caso, hace falta muchos datos para sacar todas estas conclusiones.

\subsection{El art. IX del Título Preliminar: ¿imposibilidad de negociación procesal atípica?}

La exposición anterior, en donde se echó un vistazo hacia el pasado para esclarecer aspectos importantes del papel del CPC-12 y del surgimiento del CPC-93, sirve para poder entender las particularidades de la legislación vigente. En efecto, a partir de las características antes analizadas de esta, se muestra muy natural su artículo IX:

«§ 1. Las normas procesales contenidas en este Código son de carácter imperativo, salvo regulación permisiva en contrario.

$\S 2$. Las formalidades previstas en este Código son imperativas.

$\S 3$. Sin embargo, el Juez adecuará su exigencia al logro de los fines del proceso. Cuando no se señale una formalidad específica para la realización de un acto procesal, este se reputará válido cualquiera sea la empleada».

Sería bastante común entender que las normas que se extraen de estas disposiciones normativas impedirían que las partes puedan sobreponer sus propias normas procesales convencionales a las normas previstas por la ley. Estas son imperativas e inderogables, lo cual es muy diferente, por ejemplo, del art. 190 del Código de Proceso Civil brasileño de 2015, que, expresamente, autoriza a las partes a cambiar el procedimiento "para ajustarlo a las especificidades de la causa» ${ }^{36}$. Juntamente con el art. II, III y VI, el art. IX termina por delinear la base ideológica del CPC-93: con el juez como protagonista del proceso, las normas procesales pasarían a ser de orden público y, por consiguiente, imperativas e inmodificables por las partes por medio de la negociación ${ }^{37}$.

De ahí, por ejemplo, que ni siquiera los plazos (o la falta de ellos) estén a disposición de las partes. Dice el art. 146 CPC-93: «Los plazos previstos en este Código son perentorios. No pueden ser prorrogados por las partes con relación a determinados actos procesales. La misma regla se aplica al plazo judicial. A falta de plazo legal, lo fija el Juez». He aquí una muestra más de

${ }^{36}$ Y también, recientemente, con nítida inspiración brasileña, el art. 14 del Proyecto de Reforma de Código Procesal Civil y Comercial de la Nación argentino: «Acuerdos procesales. § 1. Las partes pueden celebrar, en procesos donde se debatan derechos disponibles y en tanto no concurriera una inobservancia del orden público, acuerdos procesales que puedan determinar una modificación de las normas procesales. $§ 2$. Tales acuerdos podrán adecuar el proceso a las particularidades del conflicto y especificar el alcance de las cargas, facultades y deberes procesales de las partes. $§ 3$. De oficio o a requerimiento de parte, el juez controlará la validez de los acuerdos debiendo negar su aplicación en los casos en que lo pactado resulte nulo, suponga un abuso del derecho o importare el sometimiento a un contrato de adhesión».

37 Por más que, en mi opinión, ello esté absolutamente injustificado, en la línea de lo que defiende Cabral (2018: 168 ss.). 
férreo carácter publicista del CPC-93: aun no existiendo plazo legal las partes no podrían negociar; solo puede fijarlo el juez.

Una interpretación del art. IX § 3 llevaría a concluir que el juez está autorizado a modificar el procedimiento, dado que podría adecuar las formalidades a los fines del proceso (que serían los del art. III). No obstante, rigurosamente, en el sistema jurídico peruano el juez no posee dicho poder ya que existe la garantía del procedimiento (para las partes) prevista en el art. 139 inc. 3 $\S 2$ de la Constitución peruana: «Ninguna persona puede ser [...] sometida a procedimiento distinto de los previamente establecidos». Partiendo de la premisa de que quien diseña el procedimiento es el legislador, el juez no podría modificarlo motu proprio. Todo parece indicar, pues, que esta «adecuación de las formalidades» por parte del juez tiene que ver directamente con la validez de los actos procesales cuando no exista forma legal para practicarlos. Sin perjuicio de ello, aun cuando exista forma legal —y aun si estuviese acompañada de conminación expresa de nulidad - sería posible evitar la invalidación del acto (vid. arts. $171 \mathrm{y} \mathrm{ss.}^{38}$ ).

Pero yendo más allá del tema de las nulidades procesales, es oportuno cuestionarse si, más allá de existencia de normas expresamente permisivas (ver el siguiente ítem en que se hable de los negocios procesales típicos) ${ }^{39}$, en todo aquello no previsto por norma o formalidad expresa, las partes podrían celebrar convenciones procesales, esto es, si es que pueden negociar. Una segunda pregunta sería si estas convenciones pueden vincular al juez y, de ser el caso, de qué manera lo harían ${ }^{40}$.

Una respuesta a la primera pregunta podría partir del modelo en el que se inspiró el CPC-93, afirmando que el «espíritu de la ley» revela una auténtica apropiación de la conducción del proceso por el juez, dada la superación del modelo privatista del CPC-12 y, por tanto, que las partes no podrían tener ninguna injerencia más allá de lo que la propia ley expresamente establece. Asimismo, también podría afirmarse que, siendo el derecho procesal una especie del derecho público, todo lo que no está permitido está prohibido y, por ello, no habría margen para la autonomía de las partes.

Pienso, sin embargo, que existen buenas razones para defender soluciones radicalmente distintas. Por ejemplo, aun habiendo adoptado un modelo fuertemente publicista, el CPC-93 no afectó las libertades de las partes sobre

38 Sobre el asunto en el CPC-93, ampliamente, Cavani (2014: 285 ss.). Las normas más importantes residen en los arts. 172 §§ 2 y 4 ( «Hay también convalidación cuando el acto procesal, no obstante carecer de algún requisito formal, logra la finalidad para la que estaba destinado»; "No hay nulidad si la subsanación del vicio no ha de influir en el sentido de la resolución o en las consecuencias del acto procesal») y en el art. 174 ( $Q$ Quien formula nulidad tiene que acreditar estar perjudicado con el acto procesal viciado y, en su caso, precisar la defensa que no pudo realizar como consecuencia directa del acto procesal cuestionado. Asimismo, acreditará interés propio y específico con relación a su pedido»).

39 Entiéndase por «norma expresa» o «explícita» aquella que puede ser directa e inmediatamente reconstruida de una disposición normativa.

40 Por lo menos en mi experiencia, tales problemas no han sido colocados en la práctica forense peruana, pero no tengo cómo demostrar esa afirmación en una perspectiva general. 
el objeto litigioso y sobre las postulaciones procesales (salvo el espinoso tema de la prueba de oficio) ${ }^{41}$. Cabría cuestionar, por tanto, lo siguiente: El principio de dirección del proceso, el deber de proteger los derechos sustanciales y de promover la paz social con justicia o la «socialización del proceso» son normas que, como fue visto, más allá de delinear el modelo publicista peruano, ¿también pueden ser consideradas como criterios interpretativos para empequeñecer la libertad de las partes? Y, si acaso no fuese así, ¿cuál sería entonces el fundamento normativo ${ }^{42}$ para negar la posibilidad de negociar evitando recurrir genéricamente al «modelo»? Por lo menos en las normas del propio CPC-93, siendo un código claramente publicista, no llego a percibir tal fundamento.

Más bien, si es que hablamos de convenciones procesales y libertad de negociación de las partes, el fundamento para defenderlas estaría precisamente en la libertad de contratar reconocida en el art. 62 § 1 de la Constitución («La libertad de contratar garantiza que las partes pueden pactar válidamente según las normas vigentes al tiempo del contrato. Los términos contractuales no pueden ser modificados por leyes $\mathrm{u}$ otras disposiciones de cualquier clase $[\ldots] »)$, tal como se suele hacer para los negocios jurídicos de derecho material ${ }^{43}{ }_{-}^{44}$.

Si se interpreta el fragmento normativo del art. IX «salvo regulación permisiva en contrario» de conformidad con la norma constitucional que consa-

41 Conforme: Ariano (2003: 9). El proceso se inicia solo por iniciativa de parte (art. IV) pero tiene una excepción: el juez puede iniciar un proceso cautelar de oficio (proceso que es estructuralmente autónomo) para otorgar una pensión alimenticia cuando el vínculo de filiación sea indubitable (art. 675A) y el autor no lo haya solicitado. Asimismo, existe el deber del juez, en su decisión, de no ir más allá del pedido y de los hechos alegados por las partes (art. VII), consagrándose la congruencia, la prohibición de conocimiento privado y la prohibición de la reformatio in peius (art. $370 \S 1$ ). Naturalmente, las partes pueden celebrar negocios jurídicos materiales en el proceso, que conducen a una sentencia sobre el mérito (conciliación y transacción); pueden, también, alterar libremente la eficacia de la norma jurídica concreta contenida en la sentencia que ordena una pretensión, con excepción de la transacción (art. 339); y, como es claro, tienen libertad de realizar negocios jurídicos procesales que pueden conducir a la extinción del proceso sin decisión de mérito o por sentencias de mérito, como el caso del reconocimiento del pedido o pretensión (allanamiento y reconocimiento), desistimiento del proceso o de la pretensión, etcétera.

42 Sobre el asunto, aun cuando no sea sobre el proceso peruano, cfr. Cabral (2018: 162).

43 A esta conclusión contribuye sobremanera la posibilidad de construcción de una teoría del hecho jurídico que permita abarcar tanto el plano material como el procesal, y que el primero no esté reducido al derecho civil, como, por ejemplo, es el caso de Pontes de Miranda (1954) y Marcos Bernardes de Mello (2014). Esto, a mi juicio, permite reivindicar la presencia e importancia de la autonomía de la voluntad en la negociación procesal.

${ }_{44}$ De hecho, también sería posible interpretar que las normas sobre la libertad de contratar y prohibición de ser desviado del procedimiento permitirían, realmente, que las partes puedan negociar inclusive en contra de normas expresas imperativas del CPC-93. Esto se vería claramente potenciado a partir del entendimiento del proceso como garantía y, por ello, que la negociación de las partes, en ejercicio de su libertad, llevaría a tener una mayor protección frente al poder jurisdiccional. Con ello, podría ser derrotada la norma del art. IX por existir una antinomia con el sistema constitucional. Este argumento, sin embargo, lo dejaré para otra oportunidad. En este texto me abrazaré una interpretación bastante plausible, aunque menos ambiciosa. 
gra la libertad de contratar, la conclusión podría estructurarse a partir de lo siguiente:

a) Las normas expresas que imponen obligaciones, prohibiciones o consagran formalidades son inderogables por convención ${ }^{45}$;

b) Las partes pueden negociar si existen normas expresas permisivas que así lo autoricen (ver siguiente ítem);

c) Las partes pueden negociar si no existen normas expresas que imponen obligaciones o consagran formalidades y aun cuando no existan normas expresas permisivas.

Por esta razón no creo que sea atendible un contraargumento consistente en entender que el derecho procesal civil integra el derecho público y que, por tanto, no podría interpretarse pro libertatis. Es indiscutible que el derecho procesal civil (entendido como fragmento del sistema jurídico, y no el proceso, que es garantía para las partes que trasciende la esfera estatal) conforma el derecho público debido a la presencia del órgano jurisdiccional. Sin embargo, es altamente dudosa una aplicación del así llamado "principio de legalidad» - o, por lo menos, una de las dimensiones de este- que limita, por ejemplo, la actuación de la Administración Pública con relación a los administrados, según el cual aquella solo puede hacer exactamente lo que la ley permite y nada más que eso.

En primer lugar, la legalidad es, antes que nada, una garantía para el ciudadano de que el Estado-administrador solo actuará dentro del marco que la ley expresamente autoriza; de lo contrario, quedarían afectadas las macrogarantías de la libertad y seguridad jurídica. Siendo garantía y, por tanto, orientada siempre para contener el poder del Estado, la legalidad en la actuación del poder le aplica solo a este y nunca al ciudadano. En segundo lugar, en el derecho peruano no es posible sustentar la existencia de la norma «todo lo que no está permitido está prohibido" que pueda ser aplicable al ciudadano -incluyendo a las partes en un proceso civil- ya que la propia Constitución peruana, al consagrar el derecho-garantía de libertad, dispone exactamente lo contrario. Reza el art. 2 inc. 24, a): «nadie está obligado a hacer lo que la ley no manda ni impedido de hacer lo que ella no prohíbe». Así, no es posible construir una norma explícita o implícita que prohíba que las partes negocien sobre aquello que no esté expresamente normado por las normas infraconstitucionales del CPC-93.

Un punto importante es que el objeto de negociación por las partes reposa en las situaciones procesales de las que ellas sean titulares. Quedarían exclui-

45 Ello sin perjuicio de que esto también está sujeto a interpretación y que se podría elaborar un argumento en donde la libertad (de contratar), además de ser una norma de primer grado, también podría constituirse como una norma de segundo grado, en el sentido de ser un metacriterio que orienta la interpretación de disposiciones normativas. Este argumento, a nivel teórico, es ensayado por Humberto Ávila (2019: 12 ss.) y a nivel dogmático, referido a la legislación brasileña, por Cabral (2018: 161 ss., 288 ss.). Desarrollar este argumento me parece bastante posible, pero requeriría de una justificación más profunda. 
das, por tanto, las situaciones procesales de las que otros sujetos procesales son titulares, como partes que no suscriben dichas convenciones ${ }^{46}$. Esto sería la legislación ad actum: independientemente de los efectos jurídicos producidos por las convenciones, «todo acto de disposición debe partir del sujeto que es titular la situación procesal, o al menos de aquel que se afirma ser su titular. Las partes solo están autorizadas a deliberar sobre situaciones jurídicas que estén en su esfera de autonomía» ${ }^{47}$.

Así, si partiésemos de la premisa que efectivamente existen espacios de ejercicio legítimo de autonomía de las partes, aun en el contexto de un modelo fuertemente publicista como el peruano, el juez habría de encontrarse vinculado a la norma convencional, exactamente como lo está frente a la norma legal, esto es, las normas extraídas de documentos autoritativos expedidos por órganos estatales con competencia para ello ${ }^{48}$. Nótese que esto no quiere decir que el juez, debido a su posición como órgano judicante, no pueda controlar la validez y eficacia del negocio o de la convención ${ }^{49}$. Como todo acto jurídico, tiene inclusive el deber de hacerlo. Aún más, habrá algunas convenciones para cuya eficacia el juez debe dar su autorización o conformidad (aquí estaríamos ante un poder discrecional), otros en que esta no sería requerida y, finalmente, aquellos en que estaría restringida (como, por ejemplo, en el pacto de la competencia territorial). Como veremos en el siguiente ítem, esta vinculación (con o sin autorización) no es nada extraña en varios de los negocios y convenciones procesales típicas del propio CPC-93.

\subsection{Los negocios jurídicos procesales típicos en el CPC-93 (con especial énfasis en las convenciones procesales)}

El fuerte publicismo consagrado en la propia base del CPC-93 no presupone que los espacios de autonomía de las partes —más allá de los que tienen que ver con el principio dispositivo- hayan sido abolidos. Muy por el contrario, el legislador dejó diversos espacios para que las partes puedan acordar sobre puntos específicos del procedimiento. Seguidamente, conviene enumerar las hipótesis legales más importantes:

a) Prórroga tácita de la competencia territorial, sea por escrito (art. 25) o tácitamente (art. 26). La única hipótesis en que la competencia territorial no es prorrogable sería en materia de sucesiones, en que el juzgado competente es el del último domicilio del fallecido (art. 19).

46 Cabral (2018: 307). El autor coloca el ejemplo de situaciones de las que el juez es titular, tales como su deber de conducirse con imparcialidad, su deber de controlar la validez y eficacia de la convención, su poder de imponer multa, su deber de fallar según la carga de prueba (más allá que se pueda pactar sobre cómo esta debe ser distribuida). Aunque sean argumentos bastante atendibles, me parece que esto requeriría una reflexión adicional que no podrá ser elaborada aquí.

47 Cabral (2018: . 305).

48 Sobre el tema, cfr. Cabral (2018: 255 ss.).

49 Cabral (2018: 257 ss.). 
b) En el caso de sucesión procesal, la parte que enajenó el bien litigioso puede pedir ser excluida del proceso, lo cual está condicionado a la aceptación de la contraparte (art. $108 \S 1$ inc. 3).

c) La lengua del proceso será el español, salvo que la ley diga lo contrario o, a falta de ella, que las partes pidan que sea el quechua o el aimara, siempre que sea autorizado por el juez (art. 130, párrafo único, inc. 7).

d) Cuando la duración de la realización de actos procesales así lo exige, o cuando se trate de actuaciones urgentes cuya demora puede perjudicar una de las partes, cualquiera de ellas puede pedir la habilitación de sábados, domingos o feriados $\mathrm{u}$ horas diferentes al intervalo entre las 7 hrs y $20 \mathrm{hrs}$ (arts. 141 y 142).

e) Los hechos incontrovertidos, sea por aceptación expresa o por silencio, respuesta evasiva o negativa genérica (art. 442 párrafo único, inc. 2) llevan a la no necesidad de producir prueba sobre ellos (art. 190 § 2, inc. 1 y 2).

f) Las partes pueden pedir la suspensión del proceso, pero debe existir aprobación judicial y solo puede ser solicitada una vez en cada grado de jurisdicción, y en ningún caso puede tener una duración mayor a dos meses (art. 319).

g) A pesar de que la audiencia de conciliación haya sido suprimida del procedimiento, privilegiando, para las pretensiones sobre derechos disponibles, un procedimiento prejudicial frente a un conciliador privado (la conciliación extrajudicial), si ambas partes así lo requiriesen el juez puede convocar a audiencia de conciliación (art. 324 § 1).

h) Solo es admisible el desistimiento de la pretensión antes de la sentencia de primera instancia, salvo que sea convencional, esto es, que la otra parte dé su aceptación (art. 342 § 2).

i) Después del emplazamiento, solo es admisible el desistimiento del proceso con la concordancia expresa o tácita del demandado (art. $343 \S 1$ ).

En casos de abandono, existe renuncia a este si, luego de cuatro meses de inactividad, el beneficiado realiza un acto de impulso del proceso (art. 384 $\S 2)$.

j) Es admisible la convención sobre renuncia a recurrir contra las decisiones sobre el mérito (sea de primera o segunda instancia), siempre que sean respetados algunos requisitos tales como la renunciabilidad del derecho que sustenta la pretensión, y no se afecte el orden público, las buenas costumbres o norma imperativa (art. 361).

k) En el caso del proceso de ejecución de garantía real, el ejecutante debe ofrecer en la demanda la tasación comercial (art. 720, incs. 3 y 4). Sin perjuicio de ello, ya en la fase de la ejecución forzada (porque, en el Perú, el proceso de ejecución de título extrajudicial tiene una fase de cognición sumaria en que no existen actos de ejecución), el juez ordena una tasación para el futuro remato (art. $728 \S 1$ ). Las partes pueden acordar sobre el valor del 
bien, para evitar una nueva tasación, pero, aun así, si discrecionalmente el juez considera que el valor acordado está desactualizado, puede ordenar la tasación mediante resolución inimpugnable (art. 729 § 1).

Como puede verse, existe una fuerte presencia del juez para autorizar discrecionalmente el propio negocio jurídico o convención, además de hacer un control regular de la validez y eficacia, lo cual redunda en la consagración del elemento publicista en detrimento del poder de las partes. Solo a guisa de ejemplo, existe una gran rigidez para que el demandante modifique o amplíe su demanda, lo cual solo puede ser realizado hasta antes del emplazamiento (art. 428 - salvo el caso de pedidos accesorios, que pueden ser formulados hasta antes del saneamiento, según el art. 87 § 3) y la oportunidad de ofrecimiento de pruebas, lo cual debe ser realizado solo en los actos postulatorios (art. 189 - salvando la posibilidad de introducción de hechos y pruebas nuevas hasta la organización de la causa o en el recurso de apelación de la sentencia ex arts. 429 y 374). Llama también la atención la cantidad de restricciones que coloca el art. 332 para viabilizar el reconocimiento de la fundabilidad del pedido o de la pretensión en general incluyendo la verdad de los hechos (que, en un lenguaje ambiguo del CPC-93, sería el «allanamiento» y el «reconocimiento», respectivamente). No obstante, a pesar de todo esto, sí hay un espacio de libertad explícito en la negociación procesal.

\section{PROPUESTA: ¿QUÉ CAMINO ADOPTAR? A PROPÓSITO DEL PROYECTO DE NUEVO CÓDIGO PROCESAL CIVIL (PRCPC)}

En 2016, el Ministerio de Justicia y Derechos Humanos del Perú creó un Grupo de Trabajo encargado de revisar y proponer mejoras al Decreto Legislativo $\mathrm{N}^{\circ} 768$ (la norma que aprobó el CPC-93) ${ }^{50}$. En noviembre de 2017, el Grupo de Trabajo hizo entrega de un proyecto que traía diversas modificaciones y, en marzo de 2018, el Ministerio dispuso su publicación para conocimiento de la comunidad académica y un plazo de treinta días para enviar comentarios o sugerencias. Tiempo después, el proyecto siguió siendo trabajado y acabó por convertirse en un Proyecto de Nuevo Código Procesal Civil ${ }^{51}$.

Comentarlo in extenso este proyecto no es posible; sin embargo, en líneas generales pretendo identificar algunos aspectos que lo caracterizan:

50 El Grupo de Trabajo fue presidido por el profesor Giovanni Priori y tuvo como miembros los profesores Nelson Ramírez, Juan Luis Avendaño, Mario Reggiardo, Dante Apolín, Carmen Julia Cabello, Rolando Martel, Juan Morales, Martín Hurtado, Christian Delgado y Renzo Cavani. El secretario técnico fue el profesor Martín Sotero.

51 El proyecto puede ser encontrado en internet: https://www.gob.pe/institucion/minjus/informespublicaciones/1942518-proyecto-del-nuevo-codigo-procesal-civil. La versión previa del proyecto cuenta con una exposición de motivos que puede ser consultada aquí: http://www.gacetajuridica.com.pe/boletin-nvnet/ar-web/CPC.pdf 
i) el PRCPC busca dar un contenido más preciso a las garantías de las partes, destacando entre ellas el contradictorio (lo cual, al final, termina moderando muchísimo el publicismo abrazado por el CPC-93 ${ }^{52}$ );

ii) demuestra una clara opción por la oralidad en la fase cognitiva del proceso de conocimiento, combatiendo las reformas del CPC-93, que volvieron a los moldes de un proceso escrito (específicamente el Decreto Legislativo $\mathrm{N}^{\circ} 1069$ );

iii) se dedica a trabajar más cuidadosamente con la dogmática y la técnica legislativa (muy descuidada por el CPC-93, en parte por el hecho de que no existía doctrina o experiencia legislativa previa en la cual ampararse), optando por consagrar reglas más precisas y claras, como es el caso de los recursos, tutela provisional, ejecución y del proceso de revisión de sentencia;

iv) completa vacíos legislativos muy importantes, como es el caso de la cooperación judicial, el proceso monitorio y el proceso colectivo; y

v) elabora una reformulación de las funciones de la Corte Suprema en materia civil (que, en el Perú, frente a la falta de normas en la Constitución y en la Ley Orgánica del Poder Judicial que definan la función de la Suprema en general, esta es perfilada, en gran medida, por la legislación ordinaria). El PRCPC, es importante indicarlo, recoge problemáticas propias de la práctica forense peruana y pretende darles solución, pero tiene inspiración en las doctrinas y legislaciones brasileña, colombiana y española ${ }^{53}$.

Pues bien, ¿cuáles fueron las modificaciones más relevantes sobre el tema de las convenciones procesales? La primera y más relevante de todas es que el PRCPC alteró sustancialmente el art. IX: los $\$ \S 1$ y 2, que, como vimos consagran normas que, a su vez, imponen que las normas y formalidades procesales son imperativas, fueron abolidos. Esto es algo que no puede pasar desapercibido. El proyecto no deja de confiar en el juez como principal actor del proceso para hacer que este se encamine a su finalidad (ya no más la "paz social con justicia», sino solamente la tutela de los derechos sustanciales); sin embargo, tampoco obstaculiza que las partes celebren, antes o durante el proceso, convenciones procesales. Es verdad que no llegó a consagrar expresamente una cláusula similar a la del art. 190 del CPC brasileño, pero estamos frente a un intento que busca colocarse en un punto intermedio entre el publicismo original del CPC-93 y un proceso en que la función del juez como «dueño de la conducción del proceso» se ve notoriamente reducida.

Véase el numeral 3 del art. IX proyectado:

Las partes pueden celebrar acuerdos procesales, antes o durante el trámite del proceso, a fin de regular las situaciones jurídicas de las cuales son titulares,

52 Solo como detalle: en el art. III proyectado se eliminó la finalidad abstracta de alcanzar la paz social y justicia y, por tanto, el deber del juez de buscarla, mientras que la dicción del art. VI fue completamente modificada.

53 De lejos, la experiencia brasileña es la que mayor impacto tuvo. Esto se puede verificar en la regulación de la tutela provisional, ejecución y procesos colectivos. 
pudiendo adecuar el procedimiento al logro de sus intereses. Estos acuerdos deberán ser aprobados por el juez, salvo que la ley disponga que este se encuentra vinculado a ellos. Para la aprobación, el juez resolverá teniendo en consideración si el acuerdo está contenido en un contrato de adhesión, si una de las partes se encuentra en condición de vulnerabilidad y si los derechos discutidos en el proceso son pasibles de autocomposición. En dichos casos, el juez, previo contradictorio, declara en el mismo proceso la ineficacia del acuerdo. No se podrán celebrar convenciones procesales en contratos con cláusulas generales de contratación, pero sí en los procesos en los que se controviertan sobre ellas.

Asimismo, el PRCPC propone la creación de una audiencia preliminar en que sea discutida la improcedencia de la demanda, el saneamiento procesal, la organización de la causa y, eventualmente, en que sea emitida la sentencia (art. 264, 1, g). En la fijación de los hechos esenciales y de las pruebas destinadas a acreditarlos, el art. 264 exige que el juez escuche primeramente a las partes. El proyecto permite, inclusive, que se den acuerdos son la realización o la valoración de los medios probatorios (art. 264, 1, l) y, asimismo, en caso existan actuaciones procesales pendientes de realización (por ejemplo, la audiencia de instrucción, con la posibilidad de producción de pruebas), el juez debe preguntar a las partes si existe algún acuerdo al respecto o la posibilidad de que se acuerde sobre un calendario para la actuación probatoria (art. 264, 1, l). Se espera que, en la práctica, sea usual promover este tipo de convenciones.

Asimismo, se quiebra el monopolio del juez en lo que concierne a los plazos del procedimiento. Por ejemplo, se prevé la posibilidad de acordar sobre los plazos y fijación de calendarios (art. 140); la convención sobre la oportunidad de ofrecimiento de pruebas (según el art. 271 § 2, la regla continúa siendo en los actos postulatorios, pero se agrega que las partes pueden acordar que el ofrecimiento se dé en cualquier momento hasta la organización de la causa); la suspensión del proceso convencional hasta por tres veces en cada instancia pero solo para acudir a un centro de conciliación extrajudicial (art. 375 - sin embargo, se mantuvo el art. 370, que limita el pedido de suspensión por otras causas).

Se colocaron, además, algunas precisiones adicionales, como la posibilidad de convención sobre recurso de apelación o casación también antes del proceso (art. 561 - la norma vigente solo autoriza que sea durante la tramitación del proceso); la libertad para acordar si será requerida una garantía y, siendo así, el tipo y valor de ella, para la suspensión de los efectos de la sentencia condenatoria de primera o segunda instancia (art. 526) o también - siempre que se interprete favorablemente a la libertad de las partes_ para la no suspensión de los efectos de las sentencias declaratoria y constitutiva (art. 524) y la tutela anticipada recursal (art. 527); la vinculación del juez a la tasación convencional sin posibilidad que, discrecionalmente, pueda exigir una nueva (art. 694); el refuerzo de la libertad plena en las características de la tasación entre acreedor y deudor antes o durante el proceso (art. 758). 
Asimismo, solo en los casos de convención sobre ofrecimiento de pruebas, sobre la no impugnabilidad y sobre la garantía para la no suspensión de los efectos de la sentencia, el PRCPC colocó algunos parámetros que orientan al juez sobre cómo evaluar la validez de la convención. Esta no será válida si versa sobre derechos indisponibles o si forma parte de un contrato de adhesión. Aunque el juez, con prescindencia de que exista norma expresa, deba controlar cualquier convención teniendo en cuenta diversos criterios (no solo los mencionados, sino también otros elementos del negocio jurídico material ${ }^{54}$ ), es necesario ser muy cuidadoso con el hecho de que la (in)disponibilidad del derecho material en juicio no necesariamente afecta la libertad ni la capacidad para acordar sobre el procedimiento. En efecto, ¿por qué no sería posible celebrar convenciones procesales en un proceso de alimentos o de divorcio? Por eso prefiero, como lo hace el CPC brasileño, la expresión «derechos que admitan autocomposición».

De la misma manera, no toda convención procesal en un contrato de adhesión es por sí misma abusiva. ¿Qué ocurriría si, por ejemplo, la convención no crease ninguna desventaja efectiva para la parte adherente? En ese caso, pienso que no habría justificativa para invalidar la convención. Esto lleva a reflexionar sobre el error sistemático y la opción excesivamente protectora en que incurrió el PRCPC: error sistemático porque lo más apropiado habría sido elaborar un artículo con normas que regulen los criterios de validez y eficacia aplicables a todas las convenciones procesales; de otro lado, opción excesivamente protectora porque, frente a la interpretación favorable a la libertad de negociación de las partes y la inmensa cantidad y complejidad de las convenciones que podrían ser celebradas, se exige un control para cada caso concreto. Pienso que el art. 190 del CPC brasileño, en este punto, es un mejor ejemplo a seguir.

Algo muy relevante que no puede pasar desapercibido es que en el Perú el arbitraje se encuentra particularmente desarrollado en litigios comerciales y contra el Estado en materia de contrataciones públicas. En este último punto, tal vez haya una cuestión inédita a los ojos del procesalista extranjero: en el Perú, hace varios años, las sucesivas leyes de contrataciones con el Estado establecen que cualquier controversia obligatoriamente debe ser resuelta a través del arbitraje ${ }^{55}$. De la misma manera, desde 2008, el Perú cuenta con una ley de arbitraje elaborada a partir de la Ley-Modelo de UNCITRAL, que otorga amplios poderes a los árbitros y busca eliminar drásticamente cualquier tipo de injerencia del Judicial, sea en la elección de los árbitros, sea en el control de la sentencia arbitral (que, en el Perú, recibe el nombre de laudo arbitral) ${ }^{56}$.

\footnotetext{
54 Ampliamente, cfr. Costa e Silva (2003: 455 ss.).

55 Esto con raras excepciones, como es el caso de las discusiones sobre prestaciones adicionales de obra. Aquí estamos frente a una materia no arbitrable, por tanto, susceptible de ser reclamada ante los órganos del Judicial.

56 En el Perú, existe un importante debate académico sobre las ventajas y desventajas del arbitraje (sobre todo por recientes casos de corrupción de árbitros), incesantes capacitaciones sobre el litigio
} 
¿Por qué esto es importante? Porque el PRCPC, aun no diciéndolo en la Exposición de Motivos, se vio influenciado por la práctica arbitral peruana (de hecho, varios miembros del Grupo de Trabajo actúan en ese ámbito), en donde es muy común y hasta deseable que las partes acuerden sobre las reglas procesales, en cuyo caso las reglas convencionales sobre los plazos son muy comunes. Una práctica también presente es que en la sección del contrato referente al convenio arbitral se establezcan, con mayor o menor énfasis, diversas reglas principalmente referidas a la especie de arbitraje (de derecho o de equidad; ad hoc o institucional y, si fuese ese último, qué centro o cámara de arbitraje conducirá el proceso); a la selección de árbitros (si es árbitro único o tribunal arbitral); a la ley material o procesal aplicables; y a otros aspectos procesales como plazos, duración del arbitraje, comunicación de las decisiones del tribunal arbitral y del centro de arbitraje, etc. ${ }^{57}$. Sin embargo, no es usual acordar sobre reglas probatorias o convenciones más complejas $^{58}$.

Mi opinión es que la innovación del PRCPC es un avance muy claro, pero perfectible. Por ejemplo, pienso que es sumamente importante la existencia de una norma expresa que consagre una cláusula de convencionalidad atípica que termine por hacer traslúcida la posibilidad de que las convenciones no solo «complementen» la norma legislada, sino también la lleguen a hacer inaplicable ${ }^{59}$. Es verdad que, como fue demostrado, esto puede ser interpretado a partir de eliminación de la redacción de los aún vigentes §§ 1 y 2 del art. IX, pero una norma como la que propongo podría traer grandes ventajas sistémicas ${ }^{60}$.

Sin embargo, teniendo en cuenta que la propia cultura jurídica del litigio civil peruano está lejos de conocer el empleo de las convenciones procesales (pero no solo en el contexto del proceso, sino también en el ámbito de la negociación contractual de derecho material y en contratos más complejos), se mostraría provechoso, sin perjuicio de la existencia de una cláusula general, la previsión expresa de convenciones típicas que orienten a las partes y al juez sobre las posibilidades de negociación. Algunas de ellas podrían ser las siguientes:

arbitral y la expectativa de muchos abogados de formar parte de las listas de árbitros de las cámaras de arbitraje. Es posible decir que se trata de un medio muy popular para una parcela importante de conflictos, públicos y privados, abarcando, inclusive, reclamos laborales (sobre todo en el caso de convenios colectivos), de consumo (como opción alternativa al procedimiento sancionatorio ante INDECOPI, la entidad administrativa de consumo) y del valor de la indemnización en los casos de expropiación que es una desapropiación forzosa en favor del Estado por motivos de seguridad o necesidad pública, tal como indica el art. 70 de la Constitución peruana.

57 Conexión ya identificada, por ejemplo, por Mazzei \& Chagas (2015). La doctrina peruana especializada en el derecho de arbitraje, hasta donde llega mi conocimiento, no ha prestado atención a este punto.

${ }_{58}$ Todo ello, por lo menos, en mi experiencia personal.

59 Cfr. Cabral (2018: 165).

${ }^{60}$ Con el mismo argumento, refiriéndose al art. 190 del CPC brasileño, cfr. Cabral (2018: 166 ss.). 
- Alteración convencional de la demanda hasta la organización del proceso (que en el Perú recibe el impreciso nomen legis de «fijación de puntos controvertidos» $\left.{ }^{61}\right)$.

- Elección de la vía procedimental (ordinaria o sumaria).

- Elección de peritos o del expert, reflejando la confianza de los litigantes en un cierto profesional.

- Convención sobre la «carga de la prueba» ${ }^{62}$ y la limitación probatoria dependiendo de la naturaleza y complejidad de la causa.

- Convención sobre los poderes y oportunidad de participación del amicus curiae ${ }^{63}$.

- Alteración convencional del procedimiento de ejecución forzada de dar cuantía, cuando sea escogida la vía de la venta privada o del remate público (en este caso, por ejemplo, las publicaciones en el periódico o el sitio web, la divulgación de carteles en el lugar del inmueble, la propia subasta, etc.).

- Valor máximo y mínimo de las multas coercitivas ${ }^{64}$.

- Medidas ejecutivas a ser pedidas y ordenadas por el juez, en caso de ejecución directa ${ }^{65}$.

- Pacto sobre las costas y honorarios de abogado.

Asimismo, sería particularmente conveniente que se indique, en la regulación de las convenciones típicas, si se debe contar o no con la homologación del juez, esto es, si el juez interviene no solo en el control de validez, sino también si tiene algún poder discrecional para manifestarse sobre la oportunidad de la propia convención (como sería el caso del calendario procesal, teniendo en cuenta la cantidad de causas pendientes en el juzgado).

\section{CONCLUSIONES}

La historia del proceso civil peruano refleja algo que no es poco común en el desarrollo del proceso en otras latitudes: la apuesta por el publicismo y la consecuente disminución de los poderes de las partes en la conducción de proceso, restricción de libertades y achatamiento de la posibilidad de ne-

61 Sobre el asunto en el Perú, cfr. Cavani (2016).

62 Cfr. Ataíde Jr. \& Mouzalas (2015); Buril \& Peixoto (2015).

${ }^{6}$ Cfr. Rodrigues \& Menezes (2015).

${ }^{64}$ Cfr. Didier Jr. \& Cabral (2018). Los autores defienden que la ejecución es el lugar más propicio para la celebración de convenciones procesales, pero niegan la posibilidad de que las partes acuerden a fin de impedir al juez de hacer uso del poder coercitivo de las multas o de limitar su valor. Admiten, sin embargo, que las partes renuncien al derecho a la multa y a la ejecución de ella. No obstante, pienso que esa posición es dudosa precisamente por la razón que ofrecen para justificar la no imposición de ciertas medidas ejecutivas: la ejecución es pauteada por el interés del acreedor. Si las medidas ejecutivas tienen que ver fundamentalmente con obligaciones de contenido patrimonial vía ejecución directa, ¿cuál sería el motivo para alguna limitación en el caso de ejecución indirecta?

65 Didier Jr. \& Cabral (2018). 
gociación procesal. Sin embargo, en el caso del Perú, sin abandonar completamente el modelo en que el juez tiene gran protagonismo creado por el CPC-93, algunas concepciones sobre este pueden ser colocadas en jaque si es que se ensaya una interpretación pro libertatis acudiendo a la Constitución de 1993. No basta, pues, con argumentar del modelo sin encontrar un auténtico fundamento normativo para apagar la posibilidad de negociación entre las partes. Este fundamento, a mi juicio, no existe; más bien existe uno para afirmar lo contrario: fuera de las hipótesis de las normas expresas que impongan obligaciones o prohibiciones o consagren formalidades, sí existe libertad de negociación para las partes respecto de las situaciones jurídicas de las que ellas sean titulares, sin perjuicio del control de validez y eficacia a cargo del juez.

Asimismo, el diseño CPC-93 es parcialmente desmantelado por el PRCPC, que propone eliminar los deberes de pacificar la sociedad y de igualar a las partes (herencias del proceso publicista de la tradición austríaca) y alterar las normas que impiden que las partes celebren, con una libertad más o menos amplia, las convenciones procesales que más se ajusten a sus intereses, pasando a consagrar normas que realmente promuevan su empleo a lo largo de todo el proceso e inclusive en aspectos claves, como las pruebas y los plazos.

Todo esto quiere decir, por lo menos, dos cosas.

La primera es que, hasta un cierto grado, el modelo publicista adoptado por el CPC-93 sí sería compatible con las convenciones procesales, lo cual llevaría a una atenuación de este, y el PRCPC es una clara muestra de ello. En mi opinión, esta solución se muestra aceptable ya que el hiperpublicismo puede perfectamente decantar en arbitrariedades y termina por traicionar la verdadera naturaleza constitucional del proceso, que es la de ser una garantía para las partes frente al poder público de solucionar conflictos afectando la libertad y el patrimonio de los ciudadanos.

La segunda, que tiene más que ver con la experiencia peruana, es que el PRCPC no entiende correcto que el futuro del derecho procesal resida en la preponderancia del Estado frente a las partes, opción política que justificó el desequilibrio tan notorio entre los poderes del juez y los intereses privados consagrado por el CPC-93. Pero tampoco pretende volver atrás en la historia. El CPC-12 era una legislación para otro tiempo y poseía fallas muy graves. Algunas de ellas fueron corregidas por el CPC-93; otras, ciertamente no ${ }^{66}$. Hoy, el PRCPC busca avizorar el futuro y, con la gran influencia del arbitraje en el Perú y su inherente flexibilidad, entendió que abrir un importante margen a la negociación es la apuesta más adecuada. Con ello, la garantía del procedimiento quedaría perfectamente densificada: el juez, como autoridad que es, no puede modificar el procedimiento por sí mismo, pero las partes sí que pueden hacerlo.

\footnotetext{
${ }^{66}$ Como es el caso de la ejecución. Cfr. Ariano (1998).
} 
Felizmente, el PRCPC aún podrá continuar siendo trabajado con el objetivo de conseguir la mejor legislación procesal civil posible para el Perú.

\section{REFERENCIAS BIBLIOGRÁFICAS}

Abreu, R. S. B. (2014). Vertentes culturais do processo civil na passagem do século XIX ao século XX: as vertentes francesa e austríaca como marcos da passagem do estado liberal ao estado social e a atualidade de sua discussão. Revista de Processo 229, 89-120.

Almeida, D. A. R. (2015). A contratualização do processo. Das convenções processuais no processo civil. São Paulo: LTr.

Alzamora Valdez, M. (1953). Teoría de la acción procesal. Lima: Pontificia Universidad Católica del Perú (tese de graduação).

- (1953a). Derecho procesal civil: teoría general del proceso. Lima: Lumen.

- (1966). Derecho procesal civil: teoría del proceso ordinario. Lima: Peruana.

Ariano, E. (1998). El proceso de ejecución. La tutela ejecutiva en el Código Procesal Civil peruano (1. a ed. 1996). Lima: Rhodas (reimp.).

— (2003). Un Código de fin de siglo: el Código Procesal Civil peruano de 1993 [2000]. Problemas del proceso civil. Lima: Rhodas, 3-11.

- (2015). En los abismos de la «cultura» del proceso autoritario [2006]. In limine litis. Estudios críticos de derecho procesal civil. Lima: Instituto Pacífico, 21-37.

Ataíde Jr., J. R. (2015). Negócios jurídicos materiais e processuais - Existência, validade e eficácia. Campo-invariável e campos-dependentes: sobre os limites dos negócios jurídicos processuais. Revista de processo 244, 393-423.

Ataíde Jr., J. R \& Mouzalas, R. (2015). Distribución de la carga de la prueba por convención procesal (trad. L. Cárdenas). Convenciones procesales - Estudios sobre negocio jurídico y proceso (coords.: P. H. Nogueira \& R. Cavani). Lima: Raguel, 2015.

Ávila, H. (2019). Constituição, liberdade e interpretação. São Paulo: Malheiros.

Beneduzi, R. (2015). Introdução ao processo civil alemão. Salvador: JusPodivm.

Boitard \& Colmet-Daage, G. F. (1854). Leçons sur toutes les parties du Code de Procédure Civile, 6a ed., t. 1. Paris: Cotillon.

Buril de Macêdo, L. \& Peixoto, R. (2015). Negocios procesales sobre la distribución de la carga de la prueba (trad. L. Cárdenas). Convenciones procesales - Estudios sobre negocio jurídico y proceso (coords.: P. H. Nogueira \& R. Cavani). Lima: Raguel, 2015.

Cabral, A. P. (2018). Convenções processuais, 2. ${ }^{\text {a }}$ ed. (1. ${ }^{\mathrm{a}}$ ed.: 2015). Salvador: JusPodivm.

Cavani, R. (2014). La nulidad en el proceso civil. Lima: Palestra.

- (2016). Fijación de puntos controvertidos: una guía para jueces y árbitros. Revista de la Maestría en Derecho Procesal 6 (2), 179-200.

- (2018). Teoría impugnatoria. Recursos y revisión de la cosa juzgada en el proceso civil. Lima: Gaceta Jurídica.

Comité de Reforma Procesal (1912). Exposición de motivos del Código de procedimientos civiles. Lima: Sanmartí y Co.

Costa e Silva, P. (2003). Ato e processo. O dogma da irrelevância da vontade a interpretação e nos vícios do acto postulativo. Coimbra: Coimbra editora.

Carneiro da Cunha, L. (2015). Negocios jurídicos procesales en el proceso civil brasileño (trad. M. A. Flores). Convenciones procesales - Estudios sobre negocio jurídico y proceso (coords.: P. H. Nogueira \& R. Cavani). Lima: Raguel, 2015.

Didier Jr., F. (2015). Curso de direito processual civil - introdução ao direito processual

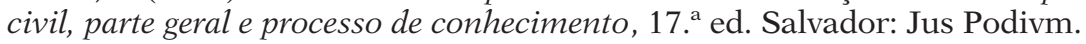


Didier Jr., F. (2015a). Cláusula general sobre el proceso en el nuevo Código de Proceso Civil brasileño (trad. R. Cavani). Convenciones procesales - Estudios sobre negocio jurídico y proceso (coords.: P. H. Nogueira \& R. Cavani). Lima: Raguel.

Didier Jr., F. \& Cabral, A. P. (2018). Negócios jurídicos processuais atípicos e execução. Revista de Processo 275, 193-228.

Didier Jr., F. \& Nogueira, P. H. (2011). Teoria dos fatos jurídicos processuais. Salvador: Jus Podivm.

- (2015). Teoría de los hechos jurídicos procesales (trad. R. Cavani). Lima: Ara.

Di Spirito, M. P. D. (2017). Comentário ao art. 190. Novo Código de Processo Civil comentado. Tomo I (art. $1^{\circ}$ ao art. 317) (coords.: Sérgio A. Ribeiro, Roberto C. Gouveia Filho, Izabel C. Pantaleão \& Lúcio G. Gouveia). São Paulo: Lualri Editora, 309-335.

Dongo Denegri, L. (1986). Derecho agrario peruano, tomo 2. Trujillo: Marsol.

Godinho, R. (2015). Negócios processuais sobre o ônus da prova no novo Código de Processo Civil. Salvador: JusPodivm.

Loret, M. (1812). Le Code de Procédure Civile, expliqué par la jurisprudence des tribunaux, t. 2. Paris: J. Gratiot.

Manresa y Navarro, J. M. (1881). Comentarios a la Ley de Enjuiciamiento Civil reformada. Madrid: Imprenta de la Revista de Legislación.

Mazzei, R. \& Chagas, B. S. R. (2015). Breve diálogo entre los negocios jurídicos procesales y el arbitraje (trad. M. L. Meza). Convenciones procesales - Estudios sobre negocio jurídico y proceso (coords.: P. H. Nogueira \& R. Cavani). Lima: Raguel, 2015.

Mello, M. B. (2014). Teoria do fato jurídico - Plano da existência, 20. ${ }^{a}$ ed. São Paulo: Saraiva.

Monroy Gálvez, J. (1996). Introducción al proceso civil, tomo 1. Bogotá-Lima: TemisEstudio De Belaúnde \& Monroy Abogados.

- (2009). La reforma del proceso civil peruano -Quince años después-. Código Procesal Civil. Lima: Communitas, 3-67.

- (2009a). Teoría general del proceso. Lima: Communitas.

- (2010). Intento de justificación [2003]. La formación del proceso civil peruano, 3. ${ }^{\mathrm{a}}$ ed. Lima: Communitas, 11-19.

— (2010a). El proceso civil en el Perú: origen y destino [1988]. La formación del proceso civil peruano, 3. ${ }^{\text {a }}$ ed. Lima: Communitas, 85-93.

- (2017). Introducción al estudio de la medida cautelar [1987]. Temas de derecho procesal, 1. Lima: Communitas.

- (2018). El cuarto de siglo del CPC. Jurídica. Suplemento de análisis legal del Diario Oficial «El Peruano», 702, 4-5.

Montero Aroca, J. (2000). La nueva Ley de Enjuiciamiento Civil española y la oralidad. Derecho PUC, 583-668.

Nogueira, P. H. (2016). Negócios jurídicos processuais. Salvador: JusPodivm.

Nogueira, P. H. \& Cavani, R. (2015). Convenciones procesales. Estudios sobre negocio jurídico y proceso, vol. 1. Lima: Raguel.

Pontes de Miranda, F. C. (1954). Tratado de direito privado (vols. 1 a 6). Rio de Janeiro: Borsoi.

Raatz, I. \& Anchieta, N. (2018). Uma «teoria do processo» sem processo? A breve história de uma ciência processual servil à jurisdição. Revista Brasileira de Direito Processual 103, 173-192.

Rodrigues, D. C. \& Menezes, R. F. F. (2015). Amicus curiae y negocios procesales en el nuevo Código de Proceso Civil brasileño (trad. M. A. Flores). Convenciones procesales - Estudios sobre negocio jurídico y proceso (coords.: P. H. Nogueira \& R. Cavani). Lima: Raguel, 2015.

Romero, J. G. (1914). Estudios de legislación procesal, vol. 1. Lima: El Lucero. 
Taruffo, M. (1980). La giustizia civile in Italia dal 700 a oggi. Bologna: Il Mulino. VV.AA. (1988). Libro Homenaje a Mario Alzamora Valdez. Lima: Cultural Cuzco.

Wijffels, A. (2005). French Civile Procedure (1806-1975). European Traditions in Civil Procedure (ed. C. van Rhee). Oxford: Intersentia. 